\title{
A review of simulation training and new 3D computer-generated synthetic organs for robotic surgery education
}

\author{
Daniel M. Costello ${ }^{1,2}$ (1) $\cdot$ Isabel Huntington ${ }^{1,2} \cdot$ Grace Burke $^{1,2} \cdot$ Brooke Farrugia $^{2,4} \cdot$ Andrea J. O'Connor ${ }^{2,4}$. \\ Anthony J. Costello ${ }^{1,2} \cdot$ Benjamin C. Thomas ${ }^{1,2} \cdot$ Philip Dundee $^{1,2} \cdot$ Ahmed Ghazi $^{3} \cdot$ Niall Corcoran $^{1,2}$
}

Received: 20 May 2021 / Accepted: 23 August 2021 / Published online: 3 September 2021

(c) The Author(s), under exclusive licence to Springer-Verlag London Ltd., part of Springer Nature 2021

\begin{abstract}
We conducted a comprehensive review of surgical simulation models used in robotic surgery education. We present an assessment of the validity and cost-effectiveness of virtual and augmented reality simulation, animal, cadaver and synthetic organ models. Face, content, construct, concurrent and predictive validity criteria were applied to each simulation model. There are six major commercial simulation machines available for robot-assisted surgery. The validity of virtual reality (VR) simulation curricula for psychomotor assessment and skill acquisition for the early phase of robotic surgery training has been demonstrated. The widespread adoption of VR simulation has been limited by the high cost of these machines. Live animal and cadavers have been the accepted standard for robotic surgical simulation since it began in the early 2000s. Our review found that there is a lack of evidence in the literature to support the use of animal and cadaver for robotic surgery training. The effectiveness of these models as a training tool is limited by logistical, ethical, financial and infection control issues. The latest evolution in synthetic organ model training for robotic surgery has been driven by new 3D-printing technology. Validated and cost-effective high-fidelity procedural models exist for robotic surgery training in urology. The development of synthetic models for the other specialties is not as mature. Expansion into multiple surgical disciplines and the widespread adoption of synthetic organ models for robotic simulation training will require the ability to engineer scalability for mass production. This would enable a transition in robotic surgical education where digital and synthetic organ models could be used in place of live animals and cadaver training to achieve robotic surgery competency.
\end{abstract}

Keywords Robotics $\cdot$ Simulation $\cdot$ Surgery $\cdot$ Training $\cdot$ Printing $\cdot$ Three dimensional $\cdot$ Cadaver $\cdot$ Virtual reality

\section{Introduction}

Robotic surgery training requires a multifaceted pathway involving various simulation platforms and didactics [1]. There are now over 5,500 Da Vinci robots installed globally and the number of surgical robots is expected to grow substantially in the next few years as new robotic vendors

Daniel M. Costello

drdancostello@gmail.com

1 Department of Surgery, The University of Melbourne, Parkville, VIC, Australia

2 The Australian Medical Robotics Academy, Melbourne, VIC, Australia

3 Simulation and Innovation Laboratory, University of Rochester Medical Center, Rochester, NY, USA

4 Department of Biomedical Engineering, The University of Melbourne, Melbourne, VIC, Australia penetrate the market driving up demand for complex robotic surgical simulation training [2]. Simulation has been fundamental to robotic surgical training since its inception in 2000 when the DaVinci surgical system received FDA approval [2]. Initial training in robotic instrumentation and buttons is conducted by the robot company representatives. The robot is then handed over to the surgeon. There is currently no standardised surgical college accredited curriculum for robotic surgery and most hospitals have arbitrary criteria as to what constitutes adequate training. The current training pathway recommended by Intuitive for the da Vinci system includes a brief online course of $3 \mathrm{~h}$, a dry laboratory session, virtual reality simulation if available, and then two pig procedures followed by two proctored live surgeries [3]. The validity of this credentialling pathway is not standardised and needs review to assess its adequacy to deliver robotic surgery competency $[4,5]$. In fact, robotic surgery was considered as one of the top ten health technology hazards in 
2015 [5]. Considering the long learning curves reported to require 300 cases for robotic prostatectomy and 50 to 100 cases for robotic gynaecological procedures, Intuitive's current recommended pathway appears inadequate [6-11]. The aim of procedural simulation is to develop surgical skills and experience prior to live surgery to reduce the risk to patients [12-14]. Higher surgical volume and experience correlates with fewer complications, shorter operative time and improved outcomes [14-19]. Existing simulation tools including virtual and augmented reality, live animals and cadavers have been used to develop robotic surgical competency. The acceptability of these simulation models has been limited by access, financial, ethical and logistical issues [20]. New synthetic organ models fabricated with 3D-printing technology may provide another viable option for proficiency-based procedural training prior to progression to live surgery. In this paper, we describe the evolution of surgical simulation models used in surgical education. We present a review of the validity and cost-effectiveness of virtual reality simulation, animal, cadaver and synthetic organ models and present a case to adopt high-fidelity organ models in place of cadavers and live animals.

\section{Methods}

A review of the literature regarding virtual reality simulation, animal and cadaver surgical simulation models for robotic and minimally invasive surgery was conducted using an electronic database (PubMed). References from reviewed articles were searched to broaden the scope of the review. Supplementary material from surgical college websites and other institutional bodies involved in robotic surgical education were also reviewed. The cost-effectiveness, acceptability and validity of these simulation models were assessed as per the terms in Fig. 1. Using the same databases and assessment criteria, we conducted a comprehensive review of synthetic organ models used in surgical training concentrating on robotic surgery in the specialties of urology, gynaecology, general surgery and colorectal. The key areas of assessment of publications on 3D computer-generated synthetic organ models were the year and location of fabrication, the intended surgical speciality and procedure, the model type, materials used, number of surgical cases conducted on the model, limitations and cost-effectiveness and validity. We focused on procedural models that could be used for robotic surgical training. The costs are reported in US dollars as priced in the year of publication.

\section{Results}

\section{Virtual and augmented reality simulation}

Virtual reality simulation involves the manipulation of computer-simulated instruments in an artificial world [21]. Virtual reality simulators can train a wide range of psychomotor skills through discrete tasks, procedural training and team training [5]. Basic robotic skills, dissection, retraction, cutting and suturing can be learned on virtual reality simulators [22]. Remote cloud-based access to simulation performance metrics enables trainees and instructors to track progress and individualise feedback. Due to the heterogeneity of the curricula included in the validation studies for virtual reality simulation, it is difficult to identify specific virtual exercises result in skill transfer into the operating room. Despite this, virtual reality simulation has been established as a valid training tool for robotic surgery [5]. Level 2 and 3 evidence for face, content and construct validity of VR simulation has been reported for the six major commercial simulation machines available for robot-assisted surgery [4, 23, 24]. These are the da Vinci skills simulator (dVSS), the Mimic da Vinci Trainer (Mimic dvTrainer), the ProMIS simulator (ProMIS), the Simsurgery Educational Platform (SEP), the
Fig. 1 Definitions of terms related to simulation cost-effectiveness and validity
Cost effectiveness - the value for money of the simulator.

Validity -

A) Face Validity: Expert review to assess whether the simulation measures what it is intended to.

B) Content Validity: Measures whether skills training on a simulator is appropriate and correct, that is, the usefulness of the simulator as a training tool.

C) Construct Validity: The ability of the simulator to differentiate between expert and novice performance.

D) Concurrent Validity: Correlating simulator performance with current surgical performance in the operating room.

E) Predictive Validity: The extent to which simulation performance will predict future performance in the live operating room $[4,21,22]$. 
Robotic Surgical Simulator (RoSS) and RobotiX Mentor. The year of release, cost and validity of these simulators are listed in Table 1. The dVSS is a backpack simulator that is attached to the robot console. The cost of this simulator is in addition to the cost of a robot console. The Mimic dvTrainer is a stand-alone simulator that replicates the vision system, hand and foot controls of the da Vinci robot. The validity of the dVSS and Mimic dvTrainer is well established in the literature. A meta-analysis by Schmidt et al. (2021) demonstrated skill transfer and predictive validity of the dvSS and Mimic dvTrainer from pooled three studies with a total of 59 participants [25]. The Mimic platform includes individual proficiency scoring where performance is compared to robotic surgeons who have performed at least 75 live cases accessible on multiple digital devices on a cloud-based system [26]. Concurrent validity was reported from five pooled studies with a total of 113 participants. Hung et al.'s 2015 augmented reality partial nephrectomy platform was added to the Mimic dvTrainer. Actual surgical footage was overlaid with interactive virtual reality content. This augmented reality system demonstrated face, content and concurrent with a live porcine model and stand-alone virtual reality exercises as comparators [1]. The ProMIS simulator is a hybrid simulator originally manufactured for laparoscopic training that has been adapted for robotic surgery training [27].ProMIS uses a mannequin and a computer interface to create and augmented reality experience [27]. Technical surgical skills acquired from using these virtual reality simulators transferred to the operating room and operating room performance were predicted by simulator performance [25]. The costs of virtual reality simulation machines is high and the cost-effectiveness of virtual reality simulators for robotic surgery has not been clearly demonstrated in the literature $[23,24]$.

\section{Animal models}

Live animal models have been used for advanced robotic surgical simulation since its inception. These models are reported to provide realistic tissue handling properties, anatomical planes and can replicate realistic bleeding [28]. There is a limited number of studies with evidence to support the use of live animal models in robotic surgical training (Table 2). Raison et al. (2021) conducted a cross-sectional survey of participants in a porcine simulation course for robotic surgery. Thirty-nine participants completed the survey yielding a response rate of $28 \%$. This low response rate means this study is at risk of bias. The self-rated responses on the effectiveness of the course suggested face and content validity. The most useful were port placement and docking, basic robotic skills training and repair of a bladder injury. Further validity assessments were not conducted. Yang et al. [29] created a laparoscopic partial nephrectomy (LPN) training model by placing a fresh porcine kidney with an artificially perfused vessel placed into a metal training box. The existing porcine vasculature was perfused and trainees resected a spherical $2 \mathrm{~cm}$ piece of parenchyma and then closed the wound. Five trainees completed ten attempts of the excision-suturing task. Simulation time decreased by $38 \%$ by the last attempt. Suture quality scores increased with consecutive attempts and all trainees reported more confidence about LPN surgical skills. Limitations of the model included a lack of tissue manipulation, a lack of surrounding realistic anatomy and a need for more realistic
Table 1 Summary of virtual reality simulator costs and validity

\begin{tabular}{|c|c|c|c|}
\hline Simulator & Year of release & Cost (USD) & Validation \\
\hline da Vinci skills simulator & 2011 & $\$ 89,000$ & $\begin{array}{l}\text { Face, content, construct, concur- } \\
\text { rent, predictive }[4,24,25]\end{array}$ \\
\hline Mimic dV trainer & 2007 & $\$ 158,000$ & $\begin{array}{l}\text { Face, content, construct, concur- } \\
\text { rent, predictive }[1,4,24,25]\end{array}$ \\
\hline ProMIS simulator & 2003 & $\$ 50,000$ & Face, content, construct $[4,24,27]$ \\
\hline Simsurgery Educational Platform & 2005 & $\$ 62,000$ & Face, content, construct $[4,24]$ \\
\hline Robotic Surgical Simulator & 2010 & $\$ 120,000$ & Face, content $[4,24]$ \\
\hline RobotiX Mentor & 2016 & $\$ 137,000$ & Face, content, construct $[4,24]$ \\
\hline
\end{tabular}

Table 2 Animal models for robotic surgical training

\begin{tabular}{|c|c|c|c|c|}
\hline Model & Skills & Study and year & Cost & Validation \\
\hline Porcine kidney & Partial nephrectomy & Yang et al. (2009) [29] & Not reported & Face, content \\
\hline Live porcine model & $\begin{array}{l}\text { Port placement and docking, basic and } \\
\text { advanced robotic skills }\end{array}$ & Raison et al. (2021) [31] & Not reported & Face, content \\
\hline Live porcine model & Left-sided pyeloplasty & Passerotti et al. (2009) [30] & Not reported & Not reported \\
\hline
\end{tabular}


perfusion pressures. Face and content validity was assessed by subjective reviews by novice surgeons who performed the simulations. The remaining validity criteria were not clearly established. The cost of the model was not reported. Passerotti et al. (2009) compared outcomes from three surgeons performing open, laparoscopic and robotic left sided pyeloplasty on 57 live pigs [30]. Surgical metrics included operative time, anastomotic time, anastomotic flow and leak test, urodynamics and histological examination of the ureteropelvic junction. The aim of this study was to compare surgical approaches rather than validate this porcine model as a training model. The learning curve of the inexperienced surgeon compared with the experienced surgeons were similar suggesting construct validity was not achieved.

\section{Cadaver models}

Cadavers have traditionally been accepted as the 'gold standard' for surgical simulation [28]. However, the evidence describing the effect of cadaveric training on surgical skills is limited (Table 3). This comprehensive review of the literature regarding cadaver surgical simulation found no studies that validated the use of cadavers in robotic surgical training.

A systematic review of the effectiveness of cadaveric surgical workshops for technical skill development was released by the College of Surgeons England systematic in 2011 [32]. This review found eight studies that met the eligibility criteria. One study from this review showed a benefit from cadaveric workshop training with regard to the ability of trainees to perform relatively simple emergency procedures [33] and one showed weak evidence of a benefit in performing more complex surgical procedures [34]. Martin et al. (1998) demonstrated objectively that the surgical skills of junior doctors improved with repeated skill training on fresh cadavers [33]. There was no empirical evidence demonstrating the transfer of cadaver surgical simulations skill into the live operating room. Several studies showed that trainees valued the experience of cadaveric training in a range of basic and advanced surgical skills [35-39]. Many of these studies relied solely on participant self-reported surveys, others employed additional objective skill metrics.

Table 3 Cadaver models

\begin{tabular}{|c|c|c|c|c|}
\hline Model & Skills & Study \& year & Cost & Validity \\
\hline Cadaver vertebrae & $\begin{array}{l}\text { Orthopaedic placement of } \\
\text { thoracic pedicle screws }\end{array}$ & Bergeson et al. (2008) [43] & NA & Content \\
\hline Fresh cadaver torso & $\begin{array}{l}\text { Chest tube insertion, endotra- } \\
\text { cheal intubation, venous cut } \\
\text { down }\end{array}$ & Martin et al. (1998) [33] & $\approx \$ 1000$ & Content, concurrent \\
\hline Cadaver torso & $\begin{array}{l}\text { Sentinel node mapping and } \\
\text { axillary lymph node dis- } \\
\text { section }\end{array}$ & Dunnington et al. (2003) [34] & $\$ 175$ & Face, content \\
\hline Fresh cadaver & Trauma surgery & Gunst et al. (2009) [38] & NA & Content \\
\hline Fresh-frozen cadaver & $\begin{array}{l}\text { Advanced cholecystectomy, } \\
\text { appendicectomy, splenec- } \\
\text { tomy, intestinal explorations, } \\
\text { mesenteric lymph node } \\
\text { biopsy and varicocoele vein } \\
\text { occlusion }\end{array}$ & Supe et al. (2005) [37] & NA & Content, face \\
\hline Fresh-frozen cadavers & Basic laparoscopic skills & Sharma et al. (2012) [44] & NA & Construct, content, predictive \\
\hline Fresh-frozen cadavers & $\begin{array}{l}\text { Advanced vascular surgical } \\
\text { skills }\end{array}$ & Mitchell et al. (2012) [39] & $\approx \$ 1000-\$ 2000$ & Content \\
\hline Theil embalmed cadaver & $\begin{array}{l}\text { Advanced laparoscopy skills: } \\
\text { colon, vascular, hernia and } \\
\text { bariatric surgery }\end{array}$ & Giger et al. (2008) [35] & $\begin{array}{l}\$ 3,534 \text { (con- } \\
\text { verted from } \\
3000 \text { Euro) }\end{array}$ & Face, content \\
\hline Thiel-embalmed cadaver & $\begin{array}{l}\text { Advanced laparoscopic renal } \\
\text { resection }\end{array}$ & Rai et al. (2015) [42] & NA & Face, content, construct \\
\hline Perfused cadaver & Multispeciality surgical skills & Carey et al. (2015) [28] & $\$ 1,262$ & Face, content \\
\hline Cadaver and benchtop models & $\begin{array}{l}\text { Burr hole insertion, chest } \\
\text { tube insertion, small bowel } \\
\text { anastomosis, flexor tendon } \\
\text { repair, K-wire fixation of a } \\
\text { metacarpal fracture }\end{array}$ & Anastakis et al. (1999) [40] & NA & Content \\
\hline Cadaver and porcine models & Basic laparoscopic skills & Katz et al. (2003) [41] & NA & Content \\
\hline Fresh-frozen cadaver & Renal transplant & Coloma et al. (2020) [45] & NA & Face, content \\
\hline
\end{tabular}


Anastakis et al. (1999) conducted a crossover trial evaluating different technical learning modalities, and reported bench and cadaver training were superior teaching tools compared to learning from reading text instructions [40]. While cadaver training scored marginally higher than bench training, they were not significantly different from each other, presumably due to the short duration (i.e. $4 \mathrm{~h}$ ) of the skills course and the small sample size. A similar study by Katz et al. (2003) that compared face and content validity of cadavers and porcine training models amongst laparoscopic trainees suggested that cadavers were a more satisfactory model for teaching anatomical and instrument techniques [41]. Carey et al. (2015) surveyed 969 trainees who reported their experience with perfused cadavers in non-robotic surgical simulations [28]. The model was rated highly for authenticity and utility for increasing knowledge, teaching new techniques, and improving procedural safety. Confidence in technical was reported to have improved after cadaver simulations. No objective skill assessments were included to confirm skill acquisition or transfer to the live operating room. The cost to perfuse a single cadaver was reported at $\$ 1,262$ USD which does not include facility fees and costs of procuring cadavers. This price is not dissimilar to nonperfused fresh-freeze cadavers, which have been reported to cost between $\approx \$ 1000-\$ 2000[33,39]$. Rai et al. (2005) conducted a study that evaluated face, content and construct validity of Thiel embalmed cadavers as a training tool for transperitoneal laparoscopic nephrectomy [42]. Twenty-four participants (4 'experts' and 20 'non-experts') devised high face validity and high content validity through a subjective questionnaire. Construct validity was demonstrated by video assessments of cadaver procedures which differentiated novice and expert performance scores. While the cost of a cadavers was not provided, the expense to acquire the infrastructure and chemicals needed to Thiel embalm one cadaver was $\$ 25,000$ and $\$ 6,250$, respectively. Another study that used Thiel-embalmed cadavers documented an expense of $\$ 3,534$ [35]. Coloma et al. (2020) demonstrated face validity for fresh-frozen cadaver renal transplant. Transfer of surgical skill to live patients was not investigated.

\section{Review of synthetic organ models for surgical training}

In this manuscript, we review the development of synthetic models for surgical training and give an overview of the utility and potential for synthetic models to replace the use of animal and cadavers in surgical simulation training in robotics. Efforts to replace live animal and cadaver surgery have been made for some time. Several physical models have been developed previously including those developed from artificial materials such as sponges, tubes and 3D-printed and tissue-based models [46-49]. These models have limitations, particularly lack of anatomic accuracy, poor haptic feedback properties, inadequate colour similarity and appearance, absence of electrosurgical utility and absence of bleeding [32, 50, 51]. Historically, the use of synthetic organ models in surgical education and planning has been primarily limited to hard plastic models. These models were intended to aid anatomical visualisation and not for full procedural simulation. Recent advancements in 3D-printing capabilities and materials engineering have seen the birth of high-fidelity soft models that replicate both the mechanical properties and colouration of human tissue [52]. Development and validation of these models as novel training tools in robotic surgery has been noted in a number of surgical fields. Our focus is on models for urology, gynaecology, general and colorectal surgery, as these disciplines are the highest users of robot assistance [53]. The desired features of a synthetic organ procedural model are realistic tissue colour and mechanical properties, bleeding capability, ability to transmit diathermy, accurate procedural steps, cost-effectiveness and validity as defined in Fig. 1. Commercially available synthetic models are not cost-effective and have not been academically validated and have therefore been excluded from this review (Figs. 2,3).

\section{Urology}

3D-printed synthetic urology organ models have evolved to become the most advanced training products in any of the surgical specialties. These models are summarised in Table 4. The clinical application of 3D-printing in urological procedures, non-robotic and robotic, is described in a systematic review by Mathews et al. (2020) [54]. Early synthetic surgical urology models lacked functionality to replicate full procedural conditions and their use was limited to surgical planning. Opik et al. 2012 developed an early prototype synthetic kidney model using patient CT data for robotic surgery training [55]. The gelatine-based models were cast using a 3D-printed mould and matched in their mechanical properties to porcine kidneys. While lacking adjacent anatomy and functionality necessary for full procedural simulation, the models demonstrated potential for an inexpensive alternative to animal and cadaver use in surgical training. These synthetic models overcame the regulatory burdens and complex handling protocols required for animal and cadaver models. These models were inert and used in the hospital operating room on the same robot used for human surgery. This can obviate the need to purchase a robot quarantined specifically for cadaver and animal surgery and thus unable to be used on humans. The early models described by Opik et al. cited limitations including the short window for use of the gelatine models and the homogeneity in the model's structure [55]. These early models were not validated for procedural training. Silberstein et al. in 2014 constructed 


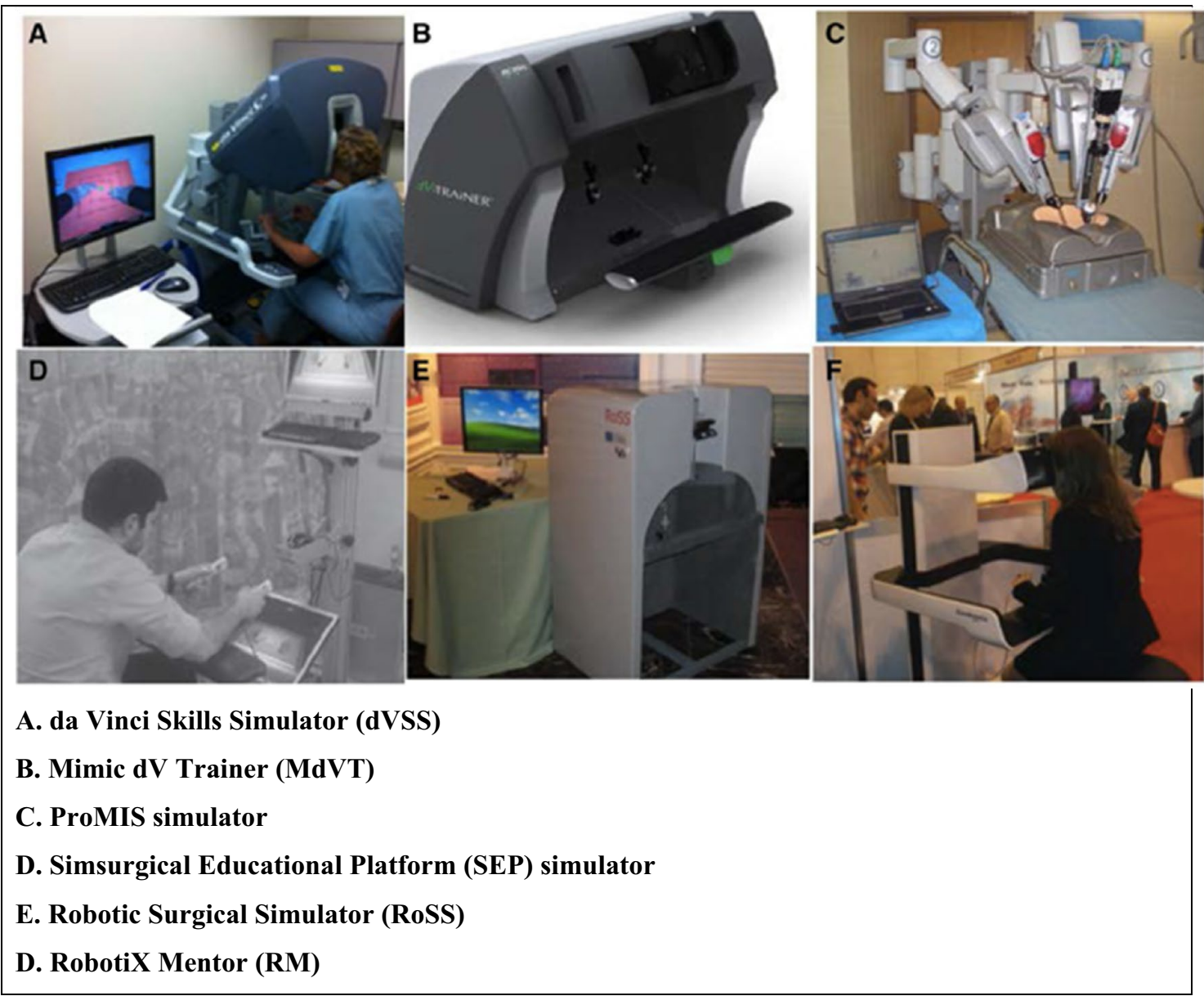

Fig. 2 Virtual reality simulators [24]

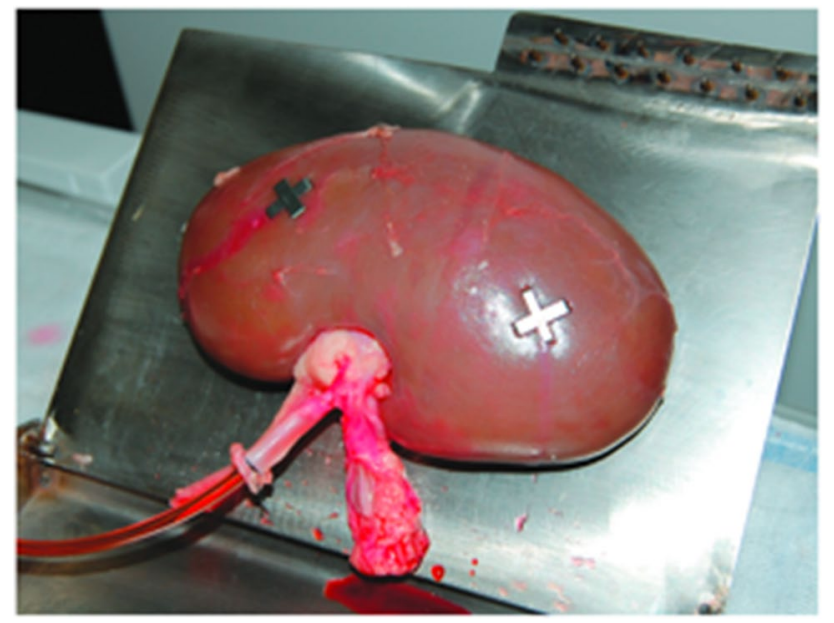

Fig. 3 Yang's Porcine Kidney Box Trainer 2009 [29]

3D-printed patient-specific renal models using a rigid resin for use in improving surgical trainee comprehension and localisation of renal masses [56]. These models included renal vasculature and the proximal collecting system and had a high degree of anatomical accuracy; however, these lacked lifelike renal tissue mechanics and colouration and hence were used only for preoperative guidance and education without a procedural simulation component. Despite anecdotal evidence of improved comprehension of the renal tumour margins from trainees, the value of these models in procedural surgical training was limited. Turney (2014) produced silicone calyceal replicas using 3D-printing technology for practice of percutaneous nephrolithotomy (PCNL) [57]. These models did not include surrounding renal parenchyma or adjacent anatomical structures. The focus of this study was on the fabrication process and material costs. This model was not clearly validated for procedural use. Adams et al. (2016) created a synthetic kidney with a collecting system from CT images using a technique that combined $3 \mathrm{D}$ wax printing and polymer moulding [58]. Face validity using endoscopic exploration of the calyces, ultrasound examination and assessment of mechanical properties was described. This model lacked bleeding capability. Von Rundstedt et al. (2017) used 3D-printing technology to fabricate 
Table 4 Synthetic organ models in urology, gynaecology, colorectal and general surgery training

\begin{tabular}{|c|c|c|c|c|c|}
\hline Author (country) year & $\begin{array}{l}\text { Speciality and proce- } \\
\text { dure }\end{array}$ & Material & No. of cases & Cost (USD) & Validation \\
\hline $\begin{array}{l}\text { Öpik et al. [55] (Esto- } \\
\text { nia/Lithuania) } 2012\end{array}$ & $\begin{array}{l}\text { Urology } \\
\text { Kidney }\end{array}$ & Gelatin & N/A & $\begin{array}{l}\text { Material cost } \$ 0.70 \text { per } \\
\text { kidney }\end{array}$ & $\begin{array}{l}\text { Face validity with porcine } \\
\text { kidney as the compara- } \\
\text { tor }\end{array}$ \\
\hline $\begin{array}{l}\text { Silberstein et al. [56] } \\
\text { (New Orleans, USA) } \\
2014\end{array}$ & $\begin{array}{l}\text { Urology } \\
\text { Partial nephrectomy }\end{array}$ & Resin & N/A & Not reported & Limited face validity \\
\hline $\begin{array}{l}\text { Turney [57] } \\
\text { (Oxford, UK) } 2014\end{array}$ & $\begin{array}{l}\text { Urology } \\
\text { PCNL }\end{array}$ & Silicone & 1 & $\begin{array}{l}\$ 119 \text { for consuma- } \\
\text { bles }+ \text { software and } \\
\text { 3D printer }\end{array}$ & $\begin{array}{l}\text { Validation criteria not } \\
\text { included }\end{array}$ \\
\hline $\begin{array}{l}\text { Adams et al. [58] } \\
\text { (Germany) } 2016\end{array}$ & $\begin{array}{l}\text { Urology } \\
\text { Flexible ureteroscopy }\end{array}$ & Wax, silicone, agarose & 10 & Not reported & $\begin{array}{l}\text { Face validity using endos- } \\
\text { copy, ultrasound and } \\
\text { mechanical assessment }\end{array}$ \\
\hline $\begin{array}{l}\text { Von Rundstedt et al. } \\
\text { [59] } \\
\text { (Houston, USA) } 2017\end{array}$ & $\begin{array}{l}\text { Urology } \\
\text { Partial nephrectomy }\end{array}$ & Silicone & 10 & Not reported & $\begin{array}{l}\text { Face, content, concurrent } \\
\text { validity }\end{array}$ \\
\hline $\begin{array}{l}\text { Choi et al. [60] } \\
\text { (Germany) 2020 }\end{array}$ & $\begin{array}{l}\text { Urology } \\
\text { TURP }\end{array}$ & PVA-based hydrogel & 9 & Not reported & $\begin{array}{l}\text { Face, content, construct } \\
\text { validity for TURP }\end{array}$ \\
\hline $\begin{array}{l}\text { Johnson et al. [21] } \\
\text { (Dallas, USA) } 2019\end{array}$ & $\begin{array}{l}\text { Urology } \\
\text { Urethrovesical anasto- } \\
\text { mosis }\end{array}$ & Silicone and resin & 20 & $\begin{array}{l}\text { Material cost } \$ 2.50 \text { per } \\
\text { model }\end{array}$ & $\begin{array}{l}\text { Low face, content, con- } \\
\text { struct validity }\end{array}$ \\
\hline $\begin{array}{l}\text { Timberlake et al. [61] } \\
\text { (USA) } 2020\end{array}$ & $\begin{array}{l}\text { Urology } \\
\text { Pyeloplasty }\end{array}$ & $\begin{array}{l}\text { Tissue-mimicking } \\
\text { silicone }\end{array}$ & 25 & Not reported & $\begin{array}{l}\text { Content, construct valid- } \\
\text { ity }\end{array}$ \\
\hline $\begin{array}{l}\text { Saba et al. [62] } \\
\text { (Rochester, USA) } 2020\end{array}$ & $\begin{array}{l}\text { Urology } \\
\text { Robot-assisted kidney } \\
\text { transplanted }\end{array}$ & PVA hydrogel & 4 & Not reported & Face, content \\
\hline $\begin{array}{l}\text { Ghazi et al. [20] (Roch- } \\
\text { ester, USA) } 2020\end{array}$ & $\begin{array}{l}\text { Urology } \\
\text { Robot-assisted partial } \\
\text { nephrectomy }\end{array}$ & PVA hydrogel & 43 & $\begin{array}{c}\text { Total material cost } \\
\$ 43.3 \text { per model }\end{array}$ & $\begin{array}{l}\text { Face, content, construct } \\
\text { validity }\end{array}$ \\
\hline $\begin{array}{l}\text { Witthaus et al. [63] } \\
\text { (Rochester, USA) } \\
2019\end{array}$ & $\begin{array}{l}\text { Urology } \\
\text { Nerve-sparing robot- } \\
\text { assisted radical } \\
\text { prostatectomy }\end{array}$ & PVA hydrogel & 14 & $\begin{array}{l}\$ 75.07 \text { in material. } \\
\$ 160 \text { in personnel } \\
\text { costs per model }\end{array}$ & $\begin{array}{l}\text { Face, content, construct } \\
\text { validity }\end{array}$ \\
\hline $\begin{array}{l}\text { Towner et al. [74] } \\
\text { (Rochester, USA) } \\
2019\end{array}$ & $\begin{array}{l}\text { Gynaecology } \\
\text { Myomectomy }\end{array}$ & PVA hydrogel & 24 & Not reported & Face, content validity \\
\hline $\begin{array}{l}\text { Marecik et al. [49] } \\
\text { (Park Ridge, USA) } \\
2008\end{array}$ & $\begin{array}{l}\text { Colorectal } \\
\text { Rectal dissection }\end{array}$ & $\begin{array}{l}\text { Silicone putty, rubber, } \\
\text { kitchen sponge }\end{array}$ & N/A & $\begin{array}{l}\$ 5 \text { per use after initial } \\
\text { model is made }\end{array}$ & Not reported \\
\hline $\begin{array}{l}\text { Wei et al. [76] } \\
\text { (China) } 2019\end{array}$ & $\begin{array}{l}\text { General } \\
\text { Pancreaticojejunostomy }\end{array}$ & Silicone & 3 & Not reported & Face \\
\hline
\end{tabular}

patient-specific silicone kidney tumour model from CTs for preprocedural partial nephrectomy rehearsal [59] (Fig. 4). These models appeared to have realistic tissue characteristics on macroscopic, ultrasound and endoscopic examination. The model replicated the tumour resection step of a robotic partial nephrectomy with objective measurement of resection time and surgical margins. While this model demonstrated potential for realistic silicone organ models, it did not replicate the steps of a full robotic partial nephrectomy procedure. Novice surgeons were not included in this study and construct and predictive validity assessments were not provided.
A mechanically realistic hydrogel model designed for educational simulation of transurethral resection of the prostate (TURP) showed promising results in its validation by Choi et al. (2020) [60]. The synthetic tissue of this model could receive electrocautery resection. Quantitative differences in surgical performances was demonstrated among an expert, an intermediate and a novice surgeon. The fabrication process for these TURP models was labour intensive and material costs were not reported. Johnson et al. (2019) fabricated a silicone radical prostatectomy model of the bony pelvis, bladder neck and urethra to simulate urethrovesical anastomosis [21]. This model had relatively low face 


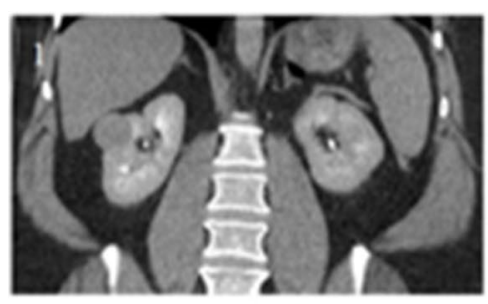

2
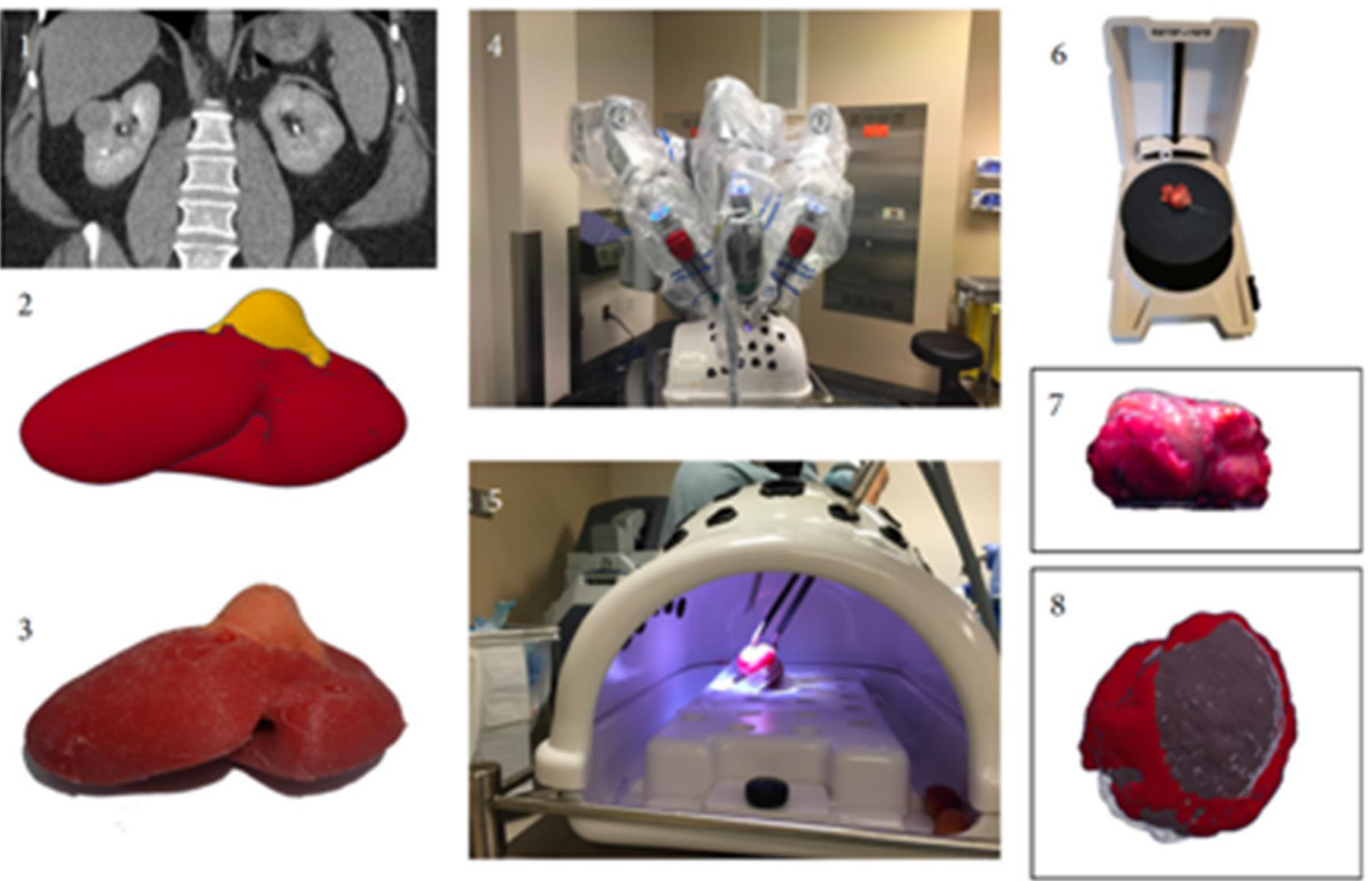

Fig. 4 Robot-assisted partial nephrectomy silicone model. Source: Von Rundstedt et al. (2017) BJUI [59]

validity. The silicone was unable to accurately replicate the compressive and elastic properties of human tissue. Content validity for urethrovesical anastomosis was reported. Construct validity assessments discriminated robotic skill level across multiple stages of training. A similar design of a lowcost silicone model for pyeloplasty simulation was produced by Timberlake et al. (2020) [61]. This model demonstrated strong potential for use in robotic training, particularly given its affordability and reproducibility. Subjective skill assessments combined with objective surgical metrics were used to establish construct validity. Content validity was reported; however face validity was not established as the model did not exactly replicate behaviour of human tissue. The silicone was stiffer and more resistant to tear than real human tissue.

Recent synthetic model construction has focused on integrating synthetic models into full procedural simulation and employing methods of validation to confirm their utility as surgical training tools in urology.

The latest development in hyper-realistic synthetic organ models is demonstrated by the Simulation Innovation Laboratory at the University of Rochester. Rochester has refined a method for producing computer-generated printed organ models using printed moulds and polyvinyl alcohol (PVA) hydrogel and have already validated some of these models. Realistic models for simulation of robotassisted kidney transplant [62] (Fig. 5), robot-assisted partial nephrectomy (Fig. 6) [20], robot-assisted radical prostatectomy [63] (Fig. 7) and penile implant surgery [64] have been validated for surgical training. These models have a high degree of anatomical and functional realism, including simulated blood flow, cautery and realistic suturability properties [65]. Saba et al.'s (2020) kidney transplant model was produced using combined 3D-printing and hydrogel casting technologies [62]. The validity of this model was limited to a single surgeon single centre study. Objective performance metrics were compared to primary published surgical outcome series and learning curves. Ghazi et al.'s (2020) hydrogel partial nephrectomy model validation study included 43 participants who performed multiple surgical simulations to establish face, content and construct validity. Assessment of transfer of skill into the live operating room was not assessed in this study [20].

Witthaus et al.'s (2020) anatomically accurate synthetic prostatectomy model includes the human pelvis, bladder, prostate, urethra, neurovascular bundle and relevant adjacent structures [63] (Fig. 7). This hydrogel-based model was created by injecting polyvinyl alcohol PVA hydrogel into a 3Dimensional printed injection mould generated from a digital reconstruction of a patient MRI. The models are created to allow a very close replication of the steps of a full nerve-sparing robotic radical prostatectomy. The steps are bladder neck dissection, seminal vesical mobilisation, and neurovascular bundle sparing and urethrovesical anastomosis. 
Fig. 5 Robot-assisted kidney transplant model. Source: Saba et al. (2020) [62]
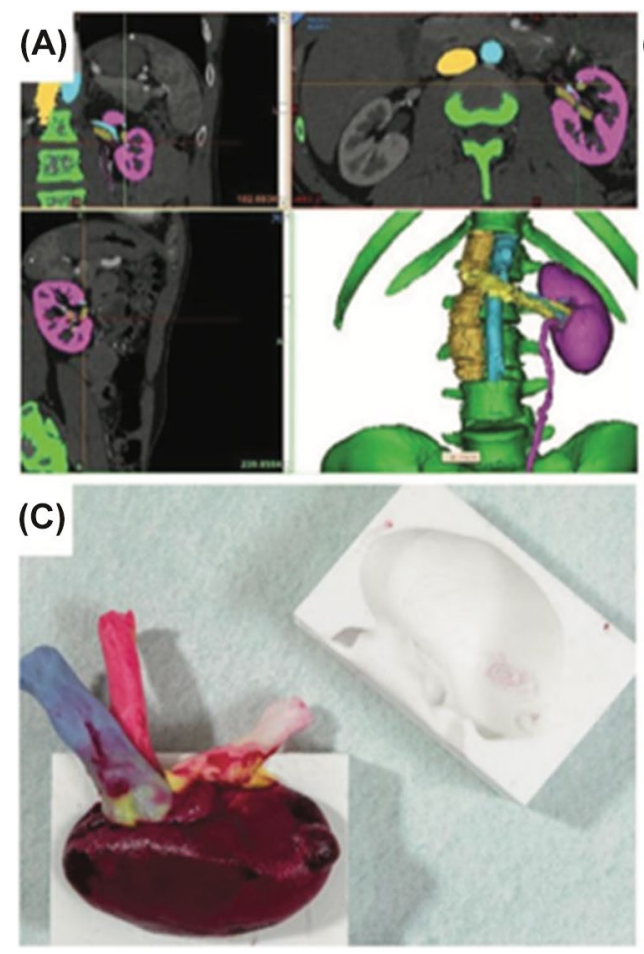

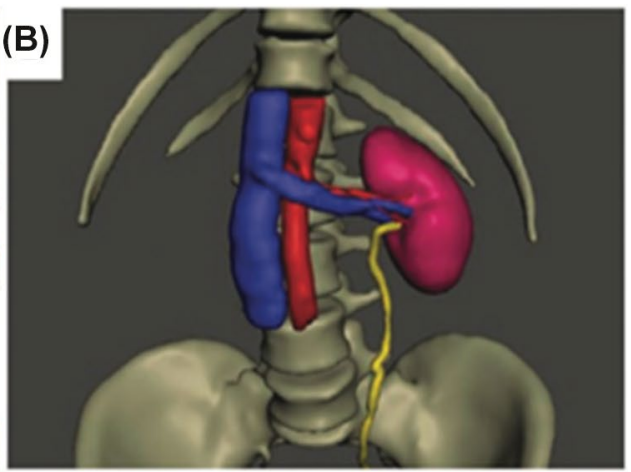

(D)

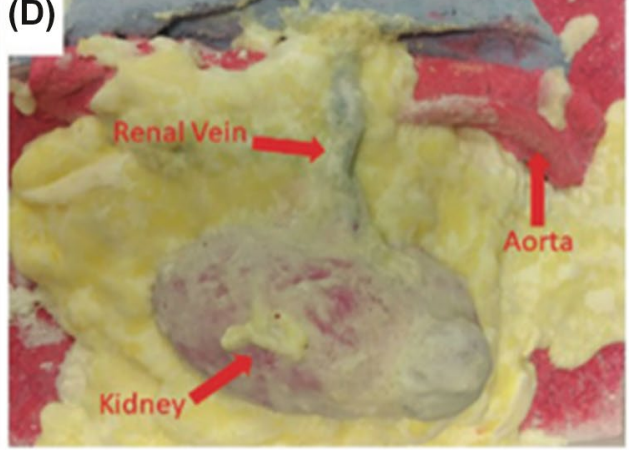

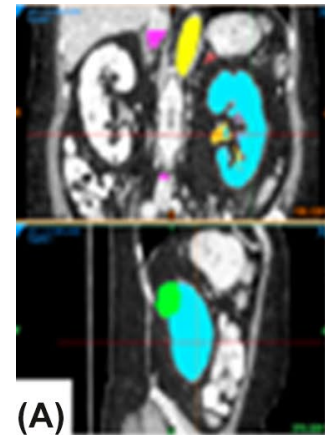

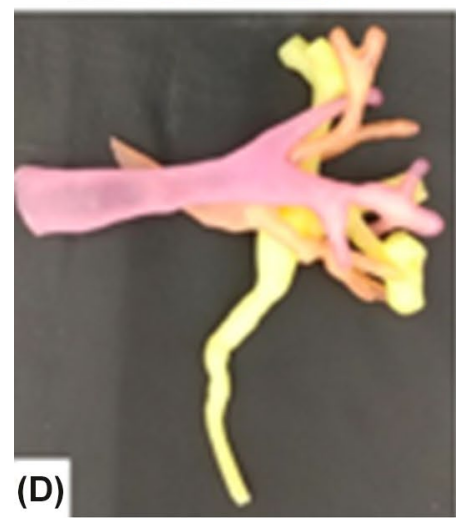

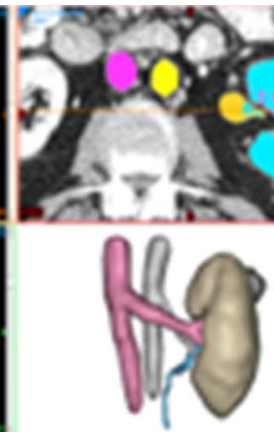

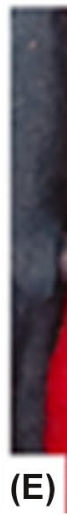

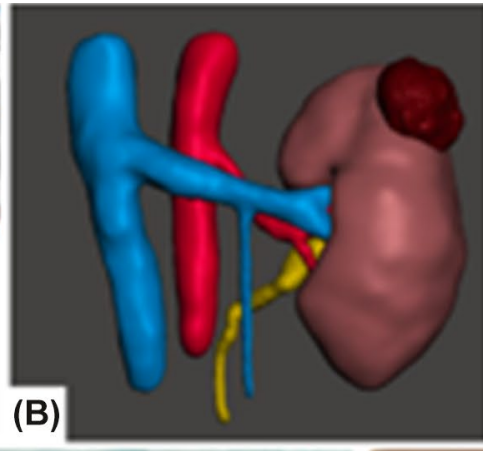

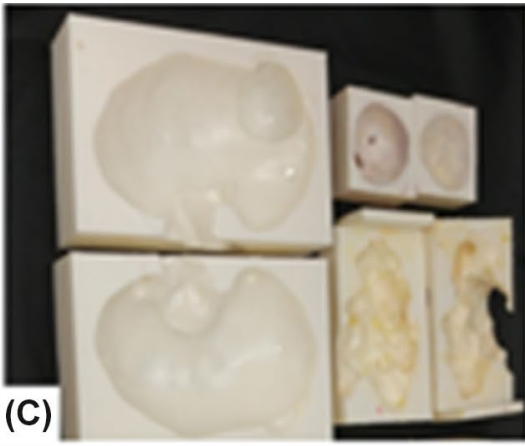

(C)

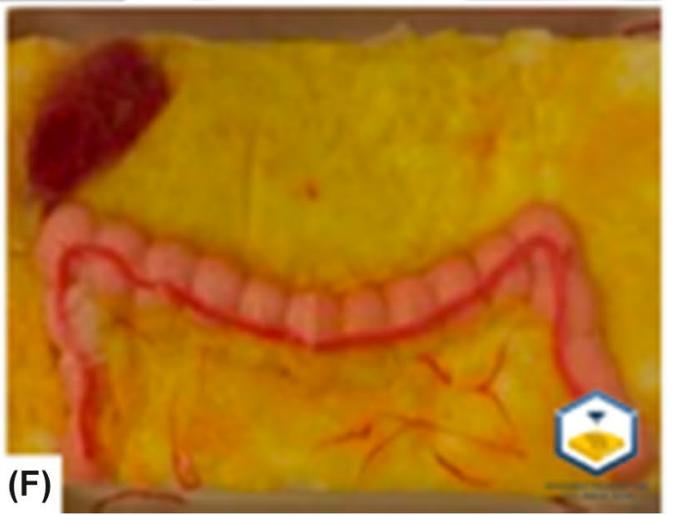

Fig. 6 Robot-assisted partial nephrectomy hydrogel model. Source: Ghazi et al. (2020) [20]

These hydrogel models are mainly constructed from inexpensive non-hazardous PVA hydrogel that increases stiffness with each successive freeze-thaw cycle to mimic the mechanical properties of the prostate gland. An MRI of a patient scheduled for robotic prostatectomy with a $40 \mathrm{~g}$ prostate and low-volume organ-confined prostate cancer was 


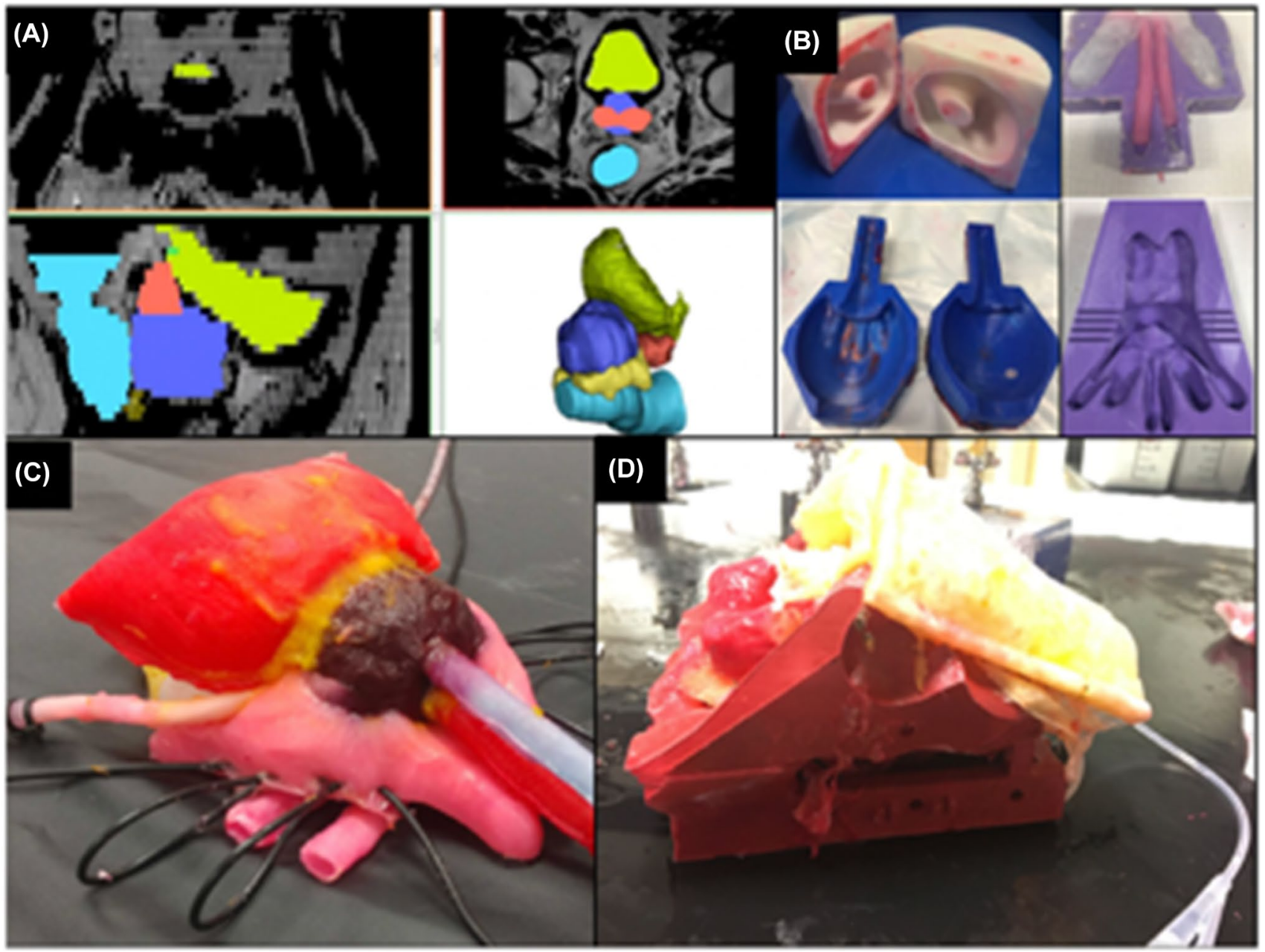

Fig. 7 Robot-assisted radical prostatectomy hydrogel model Source: Witthaus et al. (2020) [63]

obtained from radiology files which were imported to a 3D printer. The patient's pelvic organs including bony pelvis, bladder, prostate, seminal vesicle, urethra and neurovascular bundle with relevant adjacent structures were isolated by segmentation of the scan. A computer-aided design (CAD) anatomical model was made. Individual injection moulds were then designed from the CAD of the prostate, seminal vesicle, male pelvis, bladder and urethra and 3D-printed model. Polyvinyl alcohol hydrogel was injected into these models and then subjected to several freeze-thaw cycles based on the desired mechanical properties for each organ. Once removed from the corresponding moulds, the organs were cast in a series: prostate, seminal vesicle, neurovascular bundle, bladder and urethra moulds to replicate anatomical relationships between various organs. The model was perfused through the hollow, watertight vessels incorporated into the neurovascular bundle, dorsal venous complex and the prostatic pedicle during the moulding process. The final synthetic hydrogel organ model system closely replicates the human organ model system. This is in contrast to animal model constructs, which do not replicate this male genitourinary system and cadaver systems that lack tissue consistency and bleeding for realism. The entire procedure is replicated by registering the prostatectomy organ complex in its anatomic and figuration with 3D-printed male pelvis filled with pelvic floor muscles, pelvic fat and other relevant structures made of PVA. The moulding technique allows incorporation of clinically relevant objective performance metrics of simulation (CRPMS) pertinent to a radical prostatectomy surgery construct. Key metrics measured in this model included nerve tension during neurovascular bundle dissection, positive surgical margins measured with chemoluminescence, anastomotic leak test, blood loss and operating time. A unique feature of this model system is the ability to measure maximum force, average peak force frequency and total energy applied to the neurovascular bundle during dissection. This is achieved by the inclusion of nerve strain and energy gauges embedded in the neurovascular bundles that link to a computer for data capture. Objective scoring with Global Evaluative Assessment of Robotic Skills 
(GEARS) and Robotic Anastomoses Competency Evaluation (RACE) was performed by two blinded surgeons [14, 66]. GEARS scores were correlated with force applied to the neurovascular bundle and RACE scores were correlated with the vesico-urethral leak rates. CRPMS and specific expert performance ratings can be compared between novices and experts to measure construct validity. Surgical performance on these models objectively discriminated between experts and novices. Using the Ghazi prostatectomy model, experts produced $0 \%$ positive surgical cancer margins, while $77.8 \%$ of novices produced positive surgical cancer margins. Experts produced $0 \%$ anastomosis leakage, while $66 \%$ of novices demonstrated anastomosis leakage. Face validity was established experts who rated this organ system model to be most realistic for bladder neck dissection, nerve sparing, urethral anastomosis and apical dissection. Eighty percent of experts found the model to be superior to cadavers in bleeding capability, and ability to replicate all steps of the procedure and anatomical resemblance to live surgery. Experts agreed the model is suitable as a training tool that could be used as a mandatory prerequisite assessment before live surgery indicating content validity.

\section{Gynaecology}

Low-fidelity models have been used in gynaecology for some time [67]. More advanced models have been developed in recent years. Realistic synthetic simulation models for gynaecological procedures have been cited as an effective tool in surgical training and assessment in both open [68-70] and laparoscopic [71, 72] procedures. Validation of the use of synthetic models in training surgical complication management in gynaecology has also yielded very positive results. Milad et al. (2019) compared a live porcine training model with a synthetic gynaecologic pelvic model. Major vascular injury was simulated during laparoscopic access to the peritoneal cavity [73]. The synthetic model was shown to be superior to the porcine model in its feasibility for training and equally effective in simulating and instructing surgical management during complication [73]. Despite the growing utilisation of robotics in gynaecological procedures [68], there are few reports of high-fidelity synthetic organ models used for robotic surgery training. Compared with urology, uptake of 3D-printing technologies in developing synthetic models has been slower [69]. One example of the potential for success in developing high-fidelity synthetic models for robotic gynaecology training is seen in the work of Towner et al. [74]. This PVA model is designed for robotic myomectomy simulation with several anatomically accurate components, including a fallopian tube, uterus, ovary, blood vessel and $3.5 \mathrm{~cm}$ fibroid. As with previous urogenital organ models from the University of Rochester [75], these models are realistic in their elastic properties and included simulated blood flow through red-dyed saline. Qualitative surveys following 12 robotic procedures, 8 performed by resident surgeons and 4 by attendings found that $94 \%$ and $83 \%$ of residents and attendings, respectively, deemed the model to be a useful training tool. Seventy-five percent of attendings agreed that the model is valuable for assessing user ability with $87 \%$ of residents claiming they would feel more prepared for live surgery participation after practice on the model. A larger sample size, refinement of the bleeding function and improvement in mechanical properties are required in future studies of this model. Potential for unrealistic tearing of material during procedure and kinking of blood vessels during procedure were identified as limitations of the model. This model shows promise in simulation for robotic surgical education in gynaecology.

\section{General and colorectal surgery}

The number of advanced synthetic models validated for robotic training for general and colorectal surgery is limited. Some synthetic models used for education and training have been reported in the literature, yet these models typically lacked key anatomical or procedural components. Marecik et al. (2008) reported on the construction of a lowcost model for robotic rectal dissection training [49]. The model included the pelvic skeleton, pelvic floor muscles, anterior pelvic organs, rectum and mesorectum, providing a low-cost, portable and reusable surgical training model. The model was constructed without 3D printing, limiting its complexity and fidelity. Wei et al. (2019) described a 3D-printed model for robot-assisted pancreaticojejunostomy [76]. The model included a degree of functionality, including simulated pancreatic juice secretion and was considered anatomically realistic by participating surgeons. Validation was hindered by a small sample size of surgeons involved in the simulation $(n=4)$.

\section{Discussion}

It is unlikely that simulation training using the existing standard of predominantly live animals and cadavers can keep pace with the expansion of robotic surgery procedures and the need for standardised competency-based training. Virtual reality simulators are low fidelity and best suited to the early phase of training where the focus is on acquisition of correct psychomotor skills. These simulator can also assess natural aptitude for robotic surgery $[77,78]$. The cost-effectiveness of virtual reality simulators has not been clearly demonstrated and this remains a major barrier to widespread adoption of this technology. Stand-alone simulators are more accessible for training, provided the training institution has adequate funding to purchase this technology. 
Maintenance and malfunctions can generate additional costs and interruptions to training [79]. However, the validity of these machines for early surgical training is well established in the literature $[12,80]$. Currently, the computational power of virtual reality simulation machines does not deliver an experience that is equivalent to the realistic tissue handling of animal, cadaver or advanced synthetic organ models [1, 81]. Hung et al. demonstrated validity of a hybrid simulation platform that blended augmented reality, virtual reality and a porcine model for robot-assisted partial nephrectomy [1]. Experts rated augmented reality experience as useful for teaching anatomy and operative steps, but rated the porcine model overall as a more realistic experience and a more effective training and teaching tool [1].

Live animal surgery poses a significant ethical concern and animals do not accurately replicate human anatomy [55]. The evidence supporting the use of live animals for robotic surgery is sparse. Live animal training is also not cost-effective. A substantial financial investment is required to maintain access to a farm facility with live animal models, transport animals and then dispose of the animal corpses post-simulation. The Australian news story of three baboons escaping from an animal laboratory in Sydney in 2020 ("Baboon escape sparks calls for transparency in animal medical research", Sydney Morning Herald) is an example of the logistical challenges of housing live animal models for training. Animal rights organisations are critical of surgical training on live healthy animals and recommend humane alternatives [82, 83]. Some surgical college boards, such as the Australian College of Surgeons, have phased out live animal training from their formal curriculum [84]. Animal models may still have good utility for port placement. There is a need for the development of a synthetic abdominal wall to provide an alternative for this component of robotic surgical training which can be hazardous when inexperienced. It will become increasingly difficult to justify the use of live animals for surgical training when synthetic models arrive as a suitable alternative [31]. The American College of Surgeons has stated that "wherever feasible, alternatives to the use of live animals should be developed and employed [85].

Cadavers have been long considered as the highest standard of surgical simulation [28],33. However, there is a lack of studies that demonstrate concurrent or predictive validity of cadavers for surgical training and very few studies have examined their use for robotic surgery training. Qualitatively, surgical trainees and students report that they value the experience of training on cadavers. Cadavers are highly expensive, provide a single non-repeatable training episode and availability of specimens is scarce, particularly for rare or irregular pathologies [86]. Cadaver and animal models mostly lack specific pathology needed for procedural simulation, especially for cancer surgery [13]. Cadaveric and live animal models are in limited supply and storage facilities are expensive and often centralised which requires surgeons to travel to gain access to these specialised laboratories [32]. Additionally, animals and cadavers can carry a risk of spreading transferable diseases [32,79]. Guidelines vary significantly in the use of PPE and other safety measures for safe handling of COVID-19-positive corpses [87]. In some countries, the risk of COVID-19 transmission from body fluid splashes and aerosolisation from cadaver specimens has forced the suspension of cadaver simulation laboratories [87, 88]. More scientific evidence is needed to substantiate the guidelines for handling of cadavers infected with COVID19. Pandemic-related state border closures have further restricted the opportunity to access cadaver and animal training laboratories. The postponement of many non-emergent procedures, travel restriction and the closure of cadaver and animal laboratories due to COVID-19 have greatly reduced the capacity for surgical training using this method [89].

Recently published validation studies indicate strong potential for the use of realistic synthetic organ models as effective robotic surgical training tools to replace animal and cadaver training. This demand for change has been amplified by the disruption caused by COVID-19 to animal laboratories and cadaver training in anatomy departments. The ethical and financial implications of live animal and cadaver models may increase pressure to change to synthetic alternatives. Whilst urological models are more advanced in their complexity, functionality and validation, there is a demand for further development of such models across numerous specialities. In gynaecology, general and colorectal surgery, there is a need for more validated advanced procedural simulation models in these disciplines. Scalable engineering methods for mass production of the high-fidelity models are needed to increase the sample size of future validation studies and then to incorporate models into global surgical training curricula. Novel bioengineering methods reducing the time, cost and labour involved in production will help this. New models should provide a full procedural platform, with relevant adjacent organ and bony anatomic structures providing complex anatomical and functional realism. The current cost of equipment, slow fabrication time and smallscale production limit the widespread of synthetic organ models developed with 3D-printing technology [90]. Further validation studies exploring concurrent and predictive validity of these synthetic models are required.

There is a crucial need for reevaluation of the surgical training principles used in teaching robotics. Today, training time for surgical qualification is between 5 and 10 years with variations between specialities and regions [91]. College boards around the world have not adopted a standardised training curriculum for robotic surgery. A validated curriculum for robotic surgical education employing advanced synthetic model surgeries could indeed shorten surgical training time provide a realistic surgical experience prior 
to live human procedures. To meet this challenge, readily transportable 3D-printed synthetic organ models provide a logical improved training substitute.

\section{Conclusion}

We have now entered a transition phase where virtual and augmented reality systems combined with synthetic model systems provide a potential alternative to live animal and cadaver training. The validity of live animal and cadaver model training has not been clearly demonstrated for robotic surgery. The validity of perfused hydrogel models has been demonstrated in urology robotics. The development of these advanced synthetic models is not as mature yet in other surgical disciplines such as gynaecology, colorectal and general surgery. The transition to a fully digital and synthetic curriculum for robotic surgery will require the ability to engineer scalability for mass production.

\section{Declarations}

Conflict of interest None disclosed.

\section{References}

1. Hung AJ et al (2015) Development and validation of a novel robotic procedure specific simulation platform: partial nephrectomy. J Urol 194(2):520-526

2. Crew B (2020) Worth the cost? A closer look at the da Vinci robot's impact on prostate cancer surgery. Nat Index. https://doi. org/10.1038/d41586-020-01037-w

3. Intuitive (2021) Da Vinci Education. Available at https://www. intuitive.com/en-us/products-and-services/da-vinci/education. Accessed 3 Mar 2021

4. Moglia A et al (2016) A systematic review of virtual reality simulators for robot-assisted surgery. Eur Urol 69(6):1065-1080

5. Azadi $S$ et al (2021) Robotic surgery: the impact of simulation and other innovative platforms on performance and training. J Minim Invasive Gynecol 28(3):490-495

6. Tamhankar A et al (2020) Real-time assessment of learning curve for robot-assisted laparoscopic prostatectomy. Annals. https://doi. org/10.1308/rcsann.2020.0139

7. Lenihan JP Jr, Kovanda C, Seshadri-Kreaden U (2008) What is the learning curve for robotic assisted gynecologic surgery? J Minim Invas Gynecol. https://doi.org/10.1016/j.jmig.2008.06.015

8. Payne TN, Dauterive FR (2008) A comparison of total laparoscopic hysterectomy to robotically assisted hysterectomy: surgical outcomes in a community practice. J Minim Invasive Gynecol 15(3):286-291

9. Chong GO et al (2009) Learning curve of laparoscopic radical hysterectomy with pelvic and/or para-aortic lymphadenectomy in the early and locally advanced cervical cancer: comparison of the first 50 and second 50 cases. Int $\mathrm{J}$ Gynecol Cancer 19(8):1459-1464
10. Soomro NA et al (2020) Systematic review of learning curves in robot-assisted surgery. BJS open 4(1):27-44

11. Woelk JL et al (2013) The learning curve of robotic hysterectomy. Obstet Gynecol 121(1):87-95

12. Ahmed $\mathrm{K}$ et al (2011) Effectiveness of procedural simulation in urology: a systematic review. J Urol 186(1):26-34

13. Chen IHA et al (2020) Evolving robotic surgery training and improving patient safety, with the integration of novel technologies. World J Urol. https://doi.org/10.1007/s00345-020-03467-7

14. Lovegrove $C$ et al (2016) Structured and modular training pathway for robot-assisted radical prostatectomy (RARP): validation of the RARP assessment score and learning curve assessment. Eur Urol 69(3):526-535

15. Reznick RK, MacRae H (2006) Teaching surgical skills-changes in the wind. N Engl J Med 355(25):2664-2669

16. Hannan EL et al (1995) The decline in coronary artery bypass graft surgery mortality in New York State: the role of surgeon volume. JAMA 273(3):209-213

17. Sosa JA et al (1998) The importance of surgeon experience for clinical and economic outcomes from thyroidectomy. Ann Surg 228(3):320

18. Ruby ST et al (1996) Outcome analysis of carotid endarterectomy in connecticut: the impact of volume and specialty. Ann Vasc Surg 10(1):22-26

19. Gawande AA et al (2003) Analysis of errors reported by surgeons at three teaching hospitals. Surgery 133(6):614-621

20. Ghazi A et al (2020) Multi-institutional validation of a perfused robot-assisted partial nephrectomy procedural simulation platform utilizing clinically relevant objective metrics of simulators (CROMS). BJU Int. 2021 Jun;127(6):645-653. https:// doi.org/ 10.1111/bju. 15246

21. Johnson BA et al (2019) Design and validation of a low-cost, high-fidelity model for urethrovesical anastomosis in radical prostatectomy. J Endourol 33(4):331-336

22. Janetschek G (2019) Standardized and validated training programs for robot-assisted laparoscopy: the challenge of the future. Eur Urol 75(5):786-787

23. Abboudi $\mathrm{H}$ et al (2013) Current status of validation for robotic surgery simulators - a systematic review. BJU Int 111(2):194-205

24. MacCraith E, Forde JC, Davis NF (2019) Robotic simulation training for urological trainees: a comprehensive review on cost, merits and challenges. J Robot Surg 13(3):371-377

25. Schmidt MW et al (2021) Virtual reality simulation in robotassisted surgery: meta-analysis of skill transfer and predictability of skill. BJS Open. https://doi.org/10.1093/bjsopen/zraa066

26. Mimic (2021) M Score. Available at https://mimicsimulation.com/ mscore/. Accessed 3 Mar 2021

27. Feifer A et al (2011) Randomized controlled trial of virtual reality and hybrid simulation for robotic surgical training. BJU Int 108(10):1652-1656

28. Carey JN et al (2015) Perfused fresh cadavers: method for application to surgical simulation. Am J Surg 210(1):179-187

29. Yang B et al (2009) A novel training model for laparoscopic partial nephrectomy using porcine kidney. J Endourol 23(12):2029-2033

30. Passerotti CC et al (2009) Comparing the quality of the suture anastomosis and the learning curves associated with performing open, freehand, and robotic-assisted laparoscopic pyeloplasty in a swine animal model. J Am Coll Surg 208(4):576-586

31. Raison N et al (2021) An evaluation of live porcine simulation training for robotic surgery. J Robot Surg 15(3):429-434

32. Gilbody J et al (2011) The use and effectiveness of cadaveric workshops in higher surgical training: a systematic review. Ann R Coll Surg Engl 93(5):347-352

33. Martin M et al (1998) Competency-based instruction in critical invasive skills improves both resident performance and patient safety. Surgery 124(2):313-317 
34. Dunnington GL (2003) A model for teaching sentinel lymph node mapping and excision and axillary lymph node dissection. J Am Coll Surg 197(1):119-121

35. Giger $U$ et al (2008) Laparoscopic training on Thiel human cadavers: a model to teach advanced laparoscopic procedures. Surg Endosc 22(4):901-906

36. Reed AB et al (2009) Back to basics: use of fresh cadavers in vascular surgery training. Surgery 146(4):757-763

37. Supe A et al (2005) Cadaver as a model for laparoscopic training. Indian J Gastroenterol 24(3):111

38. Gunst $\mathrm{M}$ et al (2009) Trauma operative skills in the era of nonoperative management: the trauma exposure course (TEC). J Trauma Acute Care Surg 67(5):1091-1096

39. Mitchell EL et al (2012) A fresh cadaver laboratory to conceptualize troublesome anatomic relationships in vascular surgery. J Vasc Surg 55(4):1187-1194

40. Anastakis DJ et al (1999) Assessment of technical skills transfer from the bench training model to the human model. Am J Surg 177(2):167-170

41. Katz $\mathrm{R}$ et al (2003) Cadaveric versus porcine models in urological laparoscopic training. Urol Int 71(3):310-315

42. Rai BP et al (2015) Preliminary validation of Thiel embalmed cadavers for laparoscopic radical nephrectomy. J Endourol 29(5):595-603

43. Bergeson RK et al (2008) How accurately do novice surgeons place thoracic pedicle screws with the free hand technique? Spine 33(15):E501-E507

44. Sharma M et al (2012) Construct validity of fresh frozen human cadaver as a training model in minimal access surgery. JSLS 16(3):345-352

45. Coloma L et al (2020) Cadaveric models for renal transplant surgery education: a comprehensive review. Curr Urol Rep. https:// doi.org/10.1007/s11934-020-0961-x

46. Cheung CL et al (2014) Use of 3-dimensional printing technology and silicone modeling in surgical simulation: development and face validation in pediatric laparoscopic pyeloplasty. J Surg Educ 71(5):762-767

47. Alemozaffar M et al (2014) Validation of a novel, tissue-based simulator for robot-assisted radical prostatectomy. J Endourol 28(8):995-1000

48. Kiely DJ et al (2015) Advancing surgical simulation in gynecologic oncology: robotic dissection of a novel pelvic lymphadenectomy model. Simul Healthc 10(1):38-42

49. Marecik SJ et al (2008) A lifelike patient simulator for teaching robotic colorectal surgery: how to acquire skills for robotic rectal dissection. Surg Endosc 22(8):1876-1881

50. Ross HM et al (2008) Adoption of laparoscopic colectomy: results and implications of ASCRS hands-on course participation. Surg Innov 15(3):179-183

51. Van Bruwaene S et al (2015) Porcine cadaver organ or virtualreality simulation training for laparoscopic cholecystectomy: a randomized, controlled trial. J Surg Educ 72(3):483-490

52. Parikh N, Sharma $P(2018)$ Three-dimensional printing in urology: history, current applications, and future directions. Urology 121:3-10

53. Goldman Sachs Investor Talk (2020) World Robotic Symposium.

54. Mathews DAP, Baird A, Lucky M (2020) Innovation in urology: three dimensional printing and its clinical application. Front Surg 7:29. https://doi.org/10.3389/fsurg.2020.00029

55. Öpik R, et al (2012) Development of high fidelity liver and kidney phantom organs for use with robotic surgical systems. In: 2012 4th IEEE RAS \& EMBS International Conference on Biomedical Robotics and Biomechatronics (BioRob).
56. Silberstein J et al (2014) Physical Models of Renal Malignancies Using Standard Cross-sectional Imaging and 3-Dimensional Printers: A Pilot Study. Urology 84:268-273

57. Turney BW (2014) A new model with an anatomically accurate human renal collecting system for training in fluoroscopy-guided percutaneous nephrolithotomy access. J Endourol 28(3):360-363

58. Adams F et al (2017) Soft 3D-printed phantom of the human kidney with collecting system. Ann Biomed Eng 45(4):963-972

59. von Rundstedt FC et al (2017) Utility of patient-specific silicone renal models for planning and rehearsal of complex tumour resections prior to robot-assisted laparoscopic partial nephrectomy. BJU Int 119(4):598-604

60. Choi E et al (2020) A high-fidelity phantom for the simulation and quantitative evaluation of transurethral resection of the prostate. Ann Biomed Eng 48(1):437-446

61. Timberlake MD et al (2020) Design and validation of a low-cost, high-fidelity model for robotic pyeloplasty simulation training. J Pediatr Urol 16(3):332-339

62. Saba P et al (2020) Development of a high-fidelity robot-assisted kidney transplant simulation platform using three-dimensional printing and hydrogel casting technologies. J Endourol 34(10):1088-1094

63. Witthaus MW et al (2020) Incorporation and validation of clinically relevant performance metrics of simulation (CRPMS) into a novel full-immersion simulation platform for nerve-sparing robot-assisted radical prostatectomy (NS-RARP) utilizing threedimensional printing and hydrogel casting technology. BJU Int 125(2):322-332

64. van Renterghem K, Ghazi A (2020) 3D pelvic cadaver model: a novel approach to surgical training for penile implant surgery. Int J Impot Res 32(3):261-263

65. Ghazi AE, Teplitz BA (2020) Role of 3D printing in surgical education for robotic urology procedures. Transl Androl Urol 9(2):931-941

66. Ramos P et al (2014) Face, content, construct and concurrent validity of dry laboratory exercises for robotic training using a global assessment tool. BJU Int 113(5):836-842

67. Varras M et al (2020) Role of laparoscopic simulators in the development and assessment of laparoscopic surgical skills in laparoscopic surgery and gynecology (Review). World Acad Sci J 2(2):65-76

68. Miyazaki D et al (2019) Validation of an educational simulation model for vaginal hysterectomy training: a pilot study. Int Urogynecol J 30(8):1329-1336

69. Bartellas $\mathrm{M}$ et al (2017) Three-dimensional printing of a hemorrhagic cervical cancer model for postgraduate gynecological training. Cureus 9(1):e950

70. Goudie $\mathrm{C}$ et al (2018) Investigating the efficacy of anatomical silicone models developed from a $3 \mathrm{~d}$ printed mold for perineal repair suturing simulation. Cureus 10(8):e3181-e3181

71. Yousuf AA et al (2017) The development of a retroperitoneal dissection model. Am J Obstet Gynecol 217(4):483.e1-483.e3

72. Frazzini Padilla PM et al (2018) Development and validation of a simulation model for laparoscopic colpotomy. Obstet Gynecol 132(Suppl 1):19s-26s

73. Milad M et al (2017) Laparoscopic major vascular injury simulation using a synthetic compared with porcine model. Obstet Gynecol 130:24S-28S

74. Towner MN et al (2019) Creation and piloting of a model for simulating a minimally invasive myomectomy. Cureus 11(3):e4223

75. Santangelo G et al (2018) Development of a whole-task simulator for carotid endarterectomy. Oper Neurosurg (Hagerstown) 14(6):697-704

76. Wei $\mathrm{F}$ et al (2019) Three-dimensional printed dry lab training models to simulate robotic-assisted pancreaticojejunostomy. ANZ J Surg 89(12):1631-1635 
77. Moglia A et al (2014) Distribution of innate ability for surgery amongst medical students assessed by an advanced virtual reality surgical simulator. Surg Endosc 28(6):1830-1837

78. Moglia A et al (2018) Distribution of innate psychomotor skills recognized as important for surgical specialization in unconditioned medical undergraduates. Surg Endosc 32(10):4087-4095

79. Rehman S et al (2013) Simulation-based robot-assisted surgical training: a health economic evaluation. Int J Surg 11(9):841-846

80. Culligan $P$ et al (2014) Predictive validity of a training protocol using a robotic surgery simulator. Female Pelvic Med Reconstr Surg 20(1):48-51

81. Van Bruwaene S, Schijven MP, Miserez M (2014) Assessment of procedural skills using virtual simulation remains a challenge. $\mathrm{J}$ Surg Educ 71(5):654-661

82. RSPCA (2021) Lab animals. Available at: https://www.rspca.org. uk/adviceandwelfare/laboratory. Accessed 3 Mar 2021

83. PETA (2021) Animals used for experimentation. Available at https://www.peta.org/issues/animals-used-for-experimentation/. Accessed 3 Mar 2021

84. PETA (2017) VICTORY! College of Surgeons Pledges to Stop Mutilating Live Animals. Available at https://www.peta.org.au/ news/victory-college-surgeons-pledges-stop-mutilating-liveanimals/. Accessed 3 Mar 2021

85. Anon (2002) Statement on the use of animals in research, education, and teaching. Bull Am Coll Surg 87:10
86. Leblanc F et al (2010) A comparison of human cadaver and augmented reality simulator models for straight laparoscopic colorectal skills acquisition training. J Am Coll Surg 211(2):250-255

87. Dijkhuizen LGM, Gelderman HT, Duijst WLJM (2020) Review: the safe handling of a corpse (suspected) with COVID-19. J Forensic Leg Med 73:101999-101999

88. WHO (2020) Infection prevention and control for the safe management of a dead bodyin the context of COVID-19. World Health Organisation

89. Ding A, Onida S, Davies AH (2020) The painful cost of cancelling surgery due to COVID-19-can we do anything about it? Br J Surg 107(9):e336-e336

90. Martelli $\mathrm{N}$ et al (2016) Advantages and disadvantages of 3-dimensional printing in surgery: a systematic review. Surgery 159(6):1485-1500

91. Whewell $\mathrm{H}$ et al (2020) Variation in training requirements within general surgery: comparison of 23 countries. BJS Open 4(4):714-723

Publisher's Note Springer Nature remains neutral with regard to jurisdictional claims in published maps and institutional affiliations. 